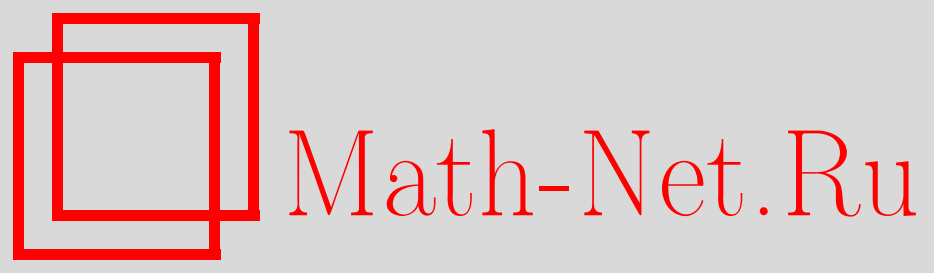

Памяти академика Анатолия Алексеевича Логунова, TMФ, 2015, том 183, номер 3, 339-341

DOI: https://doi.org/10.4213/tmf8964

Использование Общероссийского математического портала Math-Net.Ru подразумевает, что вы прочитали и согласны с пользовательским соглашением http://www . mathnet.ru/rus/agreement

Параметры загрузки:

IP: 52.6 .47 .48

26 апреля 2023 г., $07: 20: 41$

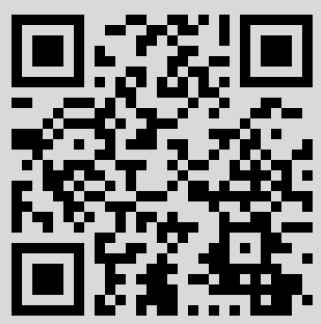




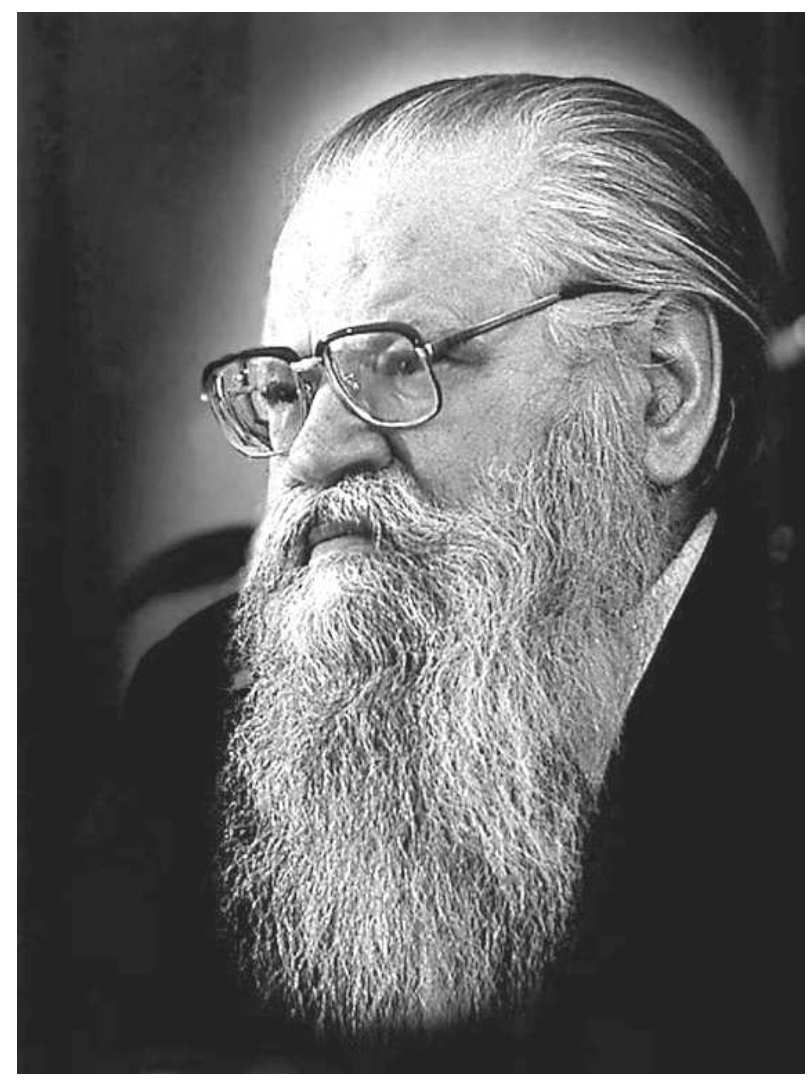

\section{Памяти академика Анатолия Алексеевича Логунова}

Отечественная и мировая наука понесла невосполнимую утрату. 1 марта 2015 года на 89-м году жизни скончался выдающийся физик-теоретик и замечательный организатор науки Анатолий Алексеевич Логунов.

А. А. Логунов родился 30 декабря 1926 года в селе Обшаровка Самарской области в рабочей семье. После окончания с отличием средней школы в г. Кузнецке он поступил в Куйбышевский авиационный институт, а затем в связи с переездом семьи перешел в Московский авиационный институт. Увлекшись на старших курсах МАИ физикой, А.А. Логунов сдал экстерном экзамены за четыре курса физического факультета МГУ и поступил в МГУ, который и закончил в 1951 году. За два года в аспирантуре он подготовил и защитил кандидатскую диссертацию, посвященную исследованию механизма стохастического ускорения космических лучей в межгалактической намагниченной плазме.

Глубокое влияние на дальнейшую научную деятельность А. А. Логунова оказало тесное научное сотрудничество с академиком Н. Н. Боголюбовым. В 1956 году он обобщил ренормгрупповые уравнения квантовой электродинамики на случай произвольной калибровки потенциалов. Вместе с основополагающими работами Н. Н. Боголюбова и Д. В. Ширкова эти исследования решили проблему последовательной формулировки методов ренормгруппы в квантовой теории поля. За эти работы в 1984 году авторам была присуждена Государственная премия СССР.

DOI: $10.4213 / \operatorname{tmf8964}$ 
А. А. Логунов успешно применил метод дисперсионных соотношений к описанию ряда процессов взаимодействия элементарных частиц. В частности, им были получены системы уравнений для описания процесса фоторождения $\pi$-мезонов на нуклонах (которое изучалось экспериментально сотрудниками Физического института АН СССР). За этот цикл работ в 1973 году А. А. Логунову и его коллегам была присуждена Государственная премия СССР. А. А. Логунов вместе с Л. Д. Соловьевым и А.Н. Тавхелидзе получил так называемые правила сумм для конечных энергий. Этот результат послужил в дальнейшем основой концепции дуальности амплитуд рассеяния, а его использование нашло наиболее плодотворное применение в квантовой хромодинамике.

Рассматривая множественное рождение частиц в реакциях при высоких энергиях, А.А. Логунов указал, что важная информация о сильном взаимодействии может быть получена при изучении так называемых инклюзивных процессов с рождением частиц одного типа. Эти работы стимулировали эксперименты на Серпуховском ускорителе, в результате которых был открыт своеобразный закон подобия - масштабная инвариантность, получившая простую интерпретацию на основе кварк-партонной модели адронов.

В последние годы А.А. Логунов был глубоко занят проблемой гравитации. Им была построена полевая (релятивистская) теория гравитации (РТГ); в ее основе лежит предположение о тензорном физическом поле в пространстве Минковского, источником которого является полный тензор энергии-импульса. Вместе с метрическим тензором в пространстве Минковского гравитационное поле создает метрику эффективного риманова пространства, т. е. теория "геометризуется" аналогично ОТО. Однако, в отличие от ОТО, в РТГ соблюдаются все законы сохранения и локализуются энергия и импульс гравитационного поля. А. А. Логунов еще в 1984 году показал, что применение РТГ к описанию Вселенной приводит к заключению о том, что ее пространственная геометрия должна быть плоской, а суммарная относительная плотность $\Omega_{\text {tot }}=1$ (т. е. должна существовать темная масса). Вплоть до самой кончины Анатолий Алексеевич упорно придерживался мысли о невозможности существования черных дыр, так как оно противоречит принципу причинности. Важным результатом, полученным им в РТГ, было то, что при сжатии звезды к гравитационному радиусу ее внутренняя энергия должна неограниченно возрастать. По его мнению, из-за неустойчивости это неизбежно должно привести к взрыву с выбросом вещества. Он надеялся, что специалисты-механики смогут решить эту задачу.

А. А. Логунов получил всеобщую известность не только как выдающийся физик, но и как замечательный прогрессивный организатор современной науки. Институт физики высоких энергий (ИФВЭ), созданный под его руководством для проведения исследований на сооружаемом в начале 60-х годов протонном ускорителе с энергией 70 ГэВ (который в то время был крупнейшим в мире), согласно предложению Анатолия Алексеевича стал с самого начала подлинным национальным центром. В исследованиях на ускорителе ИФВЭ приняли участие все институты страны, занимающиеся физикой элементарных частиц, научные центры из республик СССР, многие университеты. Для выработки программы исследований и принятия новых экспериментов был создан специальный координационный совет, собравший выдающихся ученых из разных институтов. Благодаря энергии и настойчивости А. А. Логунова удалось в краткий срок завершить сооружение ускорителя и создать его экспериментальную базу, на которой впервые в международной практике сразу после запуска ускорителя начались физические эксперименты, принесшие целый 
ряд фундаментальных открытий. Этот успех был обусловлен тем, что Анатолию Алексеевичу удалось собрать коллектив высококвалифицированных специалистов и начинающих молодых физиков-энтузиастов, которые в течение нескольких лет создавали аппаратуру для будущих исследований.

При создании научного центра Анатолию Алексеевичу удалось решить еще две трудные задачи. Он смог убедить руководство страны, во-первых, в необходимости закупки за границей отсутствующих у нас образцов вычислительной техники и, во-вторых, в необходимости широкого международного сотрудничества в исследованиях фундаментальных проблем науки. Добиться этих результатов в середине $60-\mathrm{x}$ годов было очень нелегко. Однако глубокая убежденность в необходимости решения этих вопросов позволила смело поставить их и преодолеть сопротивление среднего слоя чиновничества (как нашего, так и зарубежного). В результате наша наука вышла на новый, более высокий уровень исследований, а завязавшиеся на почве совместной работы в ИФВЭ научные связи сыграли решающую роль в дальнейшей интеграции российской и мировой науки. За разработку и ввод в действие протонного синхротрона ИФВЭ на энергию 70 ГэВ группе авторов во главе с А. А. Логуновым была присуждена Ленинская премия.

Став в 1974 году вице-президентом АН СССР, А. А. Логунов указывал, что стратегической задачей является программа создания отечественной вычислительной техники и компьютеризации страны, поскольку осуществление этой программы должно привести к развитию многих отраслей науки и техники, подобно тому как это произошло при осуществлении Атомного проекта СССР. Огромную научно-организационную работу А. А. Логунов продолжил и на посту ректора МГУ (1977-1992), сделав многое для совершенствования системы подготовки молодых ученых и для развития вузовской науки. Вместе с тем он продолжал заботиться о развитии физики высоких энергий. По его инициативе в 1980 году Правительство приняло программу, включающую создание на базе ИФВЭ ускорительно-накопительного комплекса (УНК) с фиксированной мишенью и коллайдера протонов с энергией 3 ТэВ в каждом пучке. Была принята также программа линейного электрон-позитронного коллайдера, сооружаемого ИЯФ СОАН. Интенсивные работы по созданию УНК привели к сооружению туннеля длиной 20 км и изготовлению оборудования первой очереди ускорителя. Однако с 1991 года они были прерваны из-за отсутствия финансирования. В трудные 90-е годы А.А. Логунов возвращается в институт на должность директора, а затем научного руководителя ИФВЭ. Его деятельность в этот период, по существу, спасла институт.

В знак признания научных заслуг А. А. Логунову было присвоено звание Героя социалистического труда. Он был избран иностранным членом и почетным профессором ряда Академий и университетов. С 1969 года А. А. Логунов был членом редколлегии, а в 1989 - 2013 гг. - главным редактором журнала "Теоретическая и математическая физика".

Память об Анатолии Алексеевиче сохранится навсегда в истории науки и в сердцах его учеников и коллег.

Редколлегия ТМФ 